\title{
BENJAMIN E A OBRA DE ARTE EM TEMPOS SOMBRIOS E DE TÉCNICAS DE REPRODUÇÃO
}

BENJAMIN AND THE WORK OF ART IN DARK TIMES AND OF BREEDING TECHNIQUES

Tiago Anderson Brutti

Universidade de Cruz Alta, Cruz Alta, RS, Brasil. E-mail: tiagobrutti@hotmail.com

D https://orcid.org/0000-0003-3216-4221

Antonio Escandiel de Souza

Universidade de Cruz Alta, Cruz Alta, RS, Brasil. E-mail: asouza@unicruz.edu.br

iD https://orcid.org/0000-0001-6531-3794

Fábio César Junges

Universidade de Cruz Alta, Cruz Alta, RS, Brasil. E-mail: fabiocesarjunges@yahoo.com.br

(iD https://orcid.org/0000-0002-7412-9566

Gabriela Dickel das Chagas

Universidade de Cruz Alta, Cruz Alta, RS, Brasil. E-mail: gabrieladdchagas@gmail.com

https://orcid.org/0000-0003-3032-2580

DOI: https://doi.org/10.46550/ilustracao.v1i3.54

Recebido em: 12.10.2020

Aceito em: 25.12.2020

\begin{abstract}
Resumo: Este artigo de revisão de literatura apresenta, inicialmente, a biografia de Benjamin, conforme as observaçōes de Arendt no livro "Homens em tempos sombrios", destacando a obra sui generis do escritor, sua genialidade e, também, sua má sorte, por assim dizer, em algumas circunstâncias da vida. $\mathrm{O}$ artigo é complementado por uma análise do livro "A obra de arte na época de suas técnicas de reprodução", de Benjamin. As técnicas de reprodução das obras de arte foram ampliadas e aceleradas a partir do século XX. A invençáo da fotografia, por exemplo, levou a reproduçáo da obra de arte às proximidades da perfeição. Falta-lhe, no entanto, segundo Benjamin, a aura de autenticidade, noção discutida na segunda parte deste texto.
\end{abstract}

Palavras-chave: Autenticidade; Benjamin; Obra de Arte; Reprodução técnica.

Abstract: This literature review article initially presents Benjamin's biography, according to Arendt's observations in the book "Men in dark times", highlighting the writer's sui generis work, his genius and, also, his bad luck, for so to speak, in some circumstances of life. The article is complemented by an analysis of the book "The work of art at the time of its reproduction techniques", by Benjamin. The 
reproduction techniques of works of art were expanded and accelerated from the twentieth century. The invention of photography, for example, took the reproduction of the work of art close to perfection. However, according to Benjamin, it lacks the aura of authenticity, a notion discussed in the second part of this text.

Keywords: Authenticity; Benjamin; Work of art; Technical reproduction.

\section{Introdução: Benjamin, um homem em tempos sombrios}

ascido em Berlim, em 1892, Walter Benjamin foi conhecido em vida, particularmente,
por sua atuação como colaborador de revistas e de seçóes literárias de jornais. Não obteve fama enquanto vivia, anota Arendt (1987), mas, sim, na imortalidade de sua consciência como um pensador poético. A propósito da fama, Arendt afirma que a advinda após a morte, embora menos desejada, é menos arbitrária e, muitas vezes, mais merecida, já que dificilmente se concede a uma mera mercadoria. Nessa situação, quem mais lucraria com a fama está morto e, por conseguinte, não há nada à venda.

Benjamin iniciou os estudos superiores em 1913, passando por diversas universidades, nas quais exerceu atividades políticas e culturais entre seus pares. Casou-se em 1917, passando a viver em Berna, na Suíça, onde apresentou a dissertação "O conceito de crítica de arte no romantismo alemão". Em 1921, publicou uma traduçáo dos "Quadros parisienses”, de Baudelaire. No ano seguinte, passou a publicar na revista "Novas Contribuições Alemãs". Destaca-se, nesse período, o ensaio que escreveu sobre a obra de Goethe "Afinidades eletivas". Benjamin viu frustrado seu desejo de uma carreira universitária, em 1928, quando a Universidade de Frankfurt recusou a tese "As origens da tragédia barroca na Alemanha". A fim de assegurar a sobrevivência, dedicouse à crítica jornalística e às traduçôes, tendo escrito, ainda, numerosos ensaios. Nesses últimos anos da década de 1920, traduziu para a língua alemã a obra "À procura do tempo perdido", de Proust. Não bastasse isso, planejou uma obra de filosofia da história, cujo título seria "Paris, capital do século XIX”, que ficou incompleta.

Ocorre, na década de 1930, uma série de infortúnios na vida de Benjamin: seus pais falecem, ele se divorcia da esposa e vê ascender ao poder público na Alemanha o totalitarismo nazista. Nos tempos de Hitler, ainda conseguiu publicar alguns escritos, para isso tendo de recorrer ao disfarce de pseudônimos. Em 1935, diante das ameaças do nazismo, refugiou-se em Paris, onde dirigentes emigrados do Instituto de Pesquisas Sociais o receberam como colaborador, oferecendo a ele condiçóes para escrever textos que estáo entre seus mais importantes trabalhos: "A obra de arte na época de suas técnicas de reprodução", "Alguns temas baudelairianos", "O narrador" e "Homens alemães". Por fim, Benjamin veio a falecer na fronteira entre a Espanha e a França, em circunstâncias dramáticas.

Costuma-se, assim como a Marcuse, Adorno e Horkheimer, classificar Benjamin como um dos teóricos da chamada Escola de Frankfurt, isso por causa de uma suposta similitude entre os respectivos "pensamentos", que em parte se encontram registrados nas páginas da Revista de Pesquisa Social. Com a ascensão do nacional-socialismo ao poder político da Alemanha, que instaurou um regime totalitário do qual decorre uma história de terror que envergonha a espécie humana, o Instituto de Pesquisas Sociais de Frankfurt (fundado em 1924, do qual a revista mencionada era uma espécie de porta-voz) teve de se transferir para Genebra, depois à Paris, e, 
finalmente, para Nova York. Com o fim da Segunda Guerra, os principais diretores, dentre os quais se destaca Theodor Adorno, regressaram à Alemanha e reorganizaram o Instituto.

Em tudo que escrevia, Benjamin demonstrava ser sui generis. De fato, a vida e a obra de Benjamin se destacam pela singularidade, por seu pensamento livre e cru. Considerando sua obra e perfil sob a forma de declarações negativas, temos a seguinte descrição:

[...] sua erudição era grande, mas não era um erudito; o assunto dos seus temas compreendia textos e interpretação, mas não era um filólogo; sentia-se muitíssimo atraído não pela religiâo, mas pela teologia e o tipo teológico de interpretação pelo qual o próprio texto é sagrado, mas não era teólogo, nem se interessava particularmente pela Bíblia; era um escritor nato, mas sua maior ambição era produzir uma obra que consistisse inteiramente em citaçóes; foi o primeiro alemão a traduzir Proust (juntamente com Franz Hessel) e St.-John Perse, e antes disso traduziria Quadros parisienses de Baudelaire, mas não era tradutor; resenhava livros e escreveu uma série de ensaios sobre autores vivos e mortos, mas não era um crítico literário; escreveu um livro sobre o barroco alemão e deixou um imenso estudo inacabado sobre o século XIX francês, mas não era historiador, literato ou o que for [...] ele pensava poeticamente, mas não era poeta nem filósofo (ARENDT, 1987, p. 135).

Quando, em raras ocasiôes, quis determinar o que estava fazendo no mundo da vida, identificou-se como crítico literário, apesar de não lhe agradar a ideia de ser um membro útil da sociedade. A crítica, segundo escreveu no ensaio sobre a obra "Afinidades eletivas", de Goethe, "[...] se interessa pelo conteúdo verdadeiro de uma obra de arte, o comentário pelo assunto do seu tema”. A fim de explicar esse entendimento, cabe salientar aqui o trecho:

A relação entre ambas [conteúdo verdadeiro e comentário pelo assunto do seu tema] é determinada por aquela lei básica da literatura segundo a qual o conteúdo de verdade da obra é tanto mais relevante quanto mais invisível e intimamente está ligado ao seu tema. Se, portanto, permanecem precisamente aquelas obras cuja verdade está mais profundamente encravada em seu tema, o observador que as contempla muito tempo depois de sua própria época considera as realia tanto mais extraordinárias na obra por terem desaparecido do mundo. Isso significa que o tema e o conteúdo de verdade, unidos no período inicial da obra, separamse em sua vida póstuma; o tema se torna mais extraordinário, ao passo que o conteúdo de verdade mantém seu ocultamento original. Portanto, a uma medida sempre crescente, a interpretação do extraordinário e do singular, isto é, do tema, torna-se um pré-requisito para qualquer crítico posterior (BENJAMIN apud ARENDT, 1987, p. 136).

No mesmo texto, Benjamin (apud ARENDT, 1987, p. 136) compara o crítico a um paleógrafo ou alquimista:

Pode-se compará-lo a um paleógrafo frente a um pergaminho cujo texto apagado está coberto pelos contornos mais fortes de uma escrita referente àquele texto. Assim como o paleógrafo teria de começar por ler o escrito, o crítico deve começar comentando seu texto. E, a partir dessa atividade, surge imediatamente um crítico inestimável de juízo crítico: só agora o crítico pode levantar a pergunta básica de toda a crítica - a saber, se o brilhante conteúdo de verdade da obra se deve a seu tema ou se a sobrevivência do tema se deve ao conteúdo de verdade. Pois, quando eles se separam na obra, decidem sobre a imortalidade dela. Nesse sentido, a história das obras de arte prepara a sua crítica, e é por isso que a distância histórica aumenta o seu poder. Se, para empregar uma analogia, encara-se a obra crescente como uma pira funerária, seu comentador pode ser comparado ao químico, seu 
crítico a um alquimista. Enquanto o primeiro retém a lenha e as cinzas, como únicos objetos de sua análise, o último se preocupa apenas com o enigma da própria chama: o enigma de estar viva. Assim, a crítica indaga sobre a verdade cuja chama viva continua a arder sobre os pesados troncos do passado e as leves cinzas da vida que se foi.

Realça-se, aqui, o elemento da má-sorte em sua vida. Segundo Arendt (1987), Benjamin tinha desse infortúnio uma "extraordinária consciência”. Costumava referir o "pequeno corcunda" em seus escritos. $\mathrm{Na}$ Alemanha, as mães, ao acontecer algum pequeno acidente com as crianças, costumeiramente diziam "O senhor Desajeitado manda lembranças" (Ungeschickt lässt grüssen). Com isso, a criança sabia que se tratava do "corcundinha", personagem que atrapalhava a vida pregando peças nos pequeninos. Se a criança caiu, foi ele que lhe passou uma rasteira. Se o objeto se quebrou, foi o mesmo sujeito quem o tirou da mão da criança.

A falta de sorte, atribuída ou não ao "corcundinha", sempre acompanhou Benjamin. Observe-se, agora, apenas um exemplo disso que parecia estar determinado em sua vida: sob o perigo de bombardeios, no inverno de 1939-1940, decidiu deixar Paris e migrar para um lugar mais seguro. Mas nenhuma bomba atingiu Paris, ao passo que em Meaux, para onde havia seguido, havia um centro de concentração de soldados, provavelmente um dos raros lugares franceses gravemente ameaçados naqueles tempos de guerra. De acordo com Arendt (1987, p. 141): "Sempre que tentava se adaptar e cooperar, para conseguir de algum modo um pouco de terreno sólido sob os pés, as coisas certamente desandariam."

Benjamin era fascinado pela doutrina da superestrutura. No entanto, provavelmente, náo estava interessado em sua base histórica ou filosófica, tendo utilizado essa doutrina como um estímulo heurístico-metodológico:

O que aí o fascinava era que o espírito e sua manifestação material estavam tão intimamente ligados que parecia possível descobrir em todas as partes as correspondances de Baudelaire, as quais, se fossem adequadamente correlacionadas, se esclareceriam e se iluminariam umas às outras de modo que, ao final, não mais precisariam de nenhum comentário interpretativo ou explicativo. Ele estava interessado na correlação entre uma cena de rua, uma especulação na Bolsa de Valores, um poema, um pensamento, com a linha oculta que as une e permite ao historiador ou ao filólogo reconhecer que devem ser todos situados no mesmo período (ARENDT, 1987, p. 141-42).

Apaixonado pelas coisas pequenas, Benjamin afirmava que a dimensão de um objeto era inversamente proporcional à sua significação. Essa paixão derivava, segundo Arendt (1987), da única concepção de mundo a influenciá-lo decisivamente: a convicção de Goethe acerca da existência fática de um Urphänomen, “[...] uma coisa concreta a ser descoberta no mundo das aparências, na qual coincidiriam 'significado' e aparência, palavra e coisa, ideia e experiência” (p. 142). Quanto menores fossem as coisas, mais poderiam conter tudo sob a mais concentrada forma.

Ao pensar poeticamente, estava fadado a considerar como maior dom da linguagem a

1 O pequeno corcunda (bucklicht Männlein) é um personagem de conto de fadas alemão, de Des Knaben Wunderhorn, a famosa coletânea da poesia popular alemã: "Will ich in mein'Keller gehn, - Will mein Weinlein zapten; - Steht ein bucklicht Mannlein da, - Tät mir'n Krug wegschnappen. - Will ich in mein Küchel gehn, - Will mein Süpplein kochen; - Steht ein bucklicht Männlein da, - Hat mein Töpflein brochen” [Vou à minha adega, beber o meu vinho, lá está um corcundinha, pegou minha garrafinha. Vou à minha cozinha, cozinhar minha sopinha, lá está um corcundinha, quebrou minha panelinha] (ARENDT, 1987, p. 137). 
metáfora: "As metáforas são os meios pelos quais se realiza poeticamente a unicidade do mundo". Essa "transferência" linguística permitiria dar forma material ao abstrato ou ao invisível e tornálo passível de ser experimentado: "Parece plausível que Benjamin, cuja existência espiritual se formara e enformara por Goethe, um poeta e não um filósofo, e cujo interesse era despertado quase que exclusivamente por poetas e romancistas, embora tivesse estudado filosofia, deveria achar mais fácil se comunicar com poetas do que com teóricos, fossem eles da variante dialética ou metafísica” (ARENDT, 1987, p. 144).

Da amizade com Brecht, considerado um golpe de sorte em sua vida, Benjamin pôde exercitar o que seu amigo chamou de "pensamento cru". Para explicar essa forma de pensar, argumenta: "Há muitas pessoas que imaginam que um dialético é um amante de sutilezas [...] Os pensamentos crus, pelo contrário, deveriam fazer parte e parcela do pensamento dialético, pois não são senão a referência da teoria à prática [...] um pensamento deve ser cru para se converter em ação" (BENJAMIN apud ARENDT, 1987, p. 145).

Quando estava prestes a emigrar para os Estados Unidos, a fim de fugir do terror nazifascista, Benjamin se suicidou na fronteira franco-espanhola. Era 26 de setembro de 1940. Segundo Arendt (1987), estão entre as razóes para essa trágica atitude de dar cabo à vida, provavelmente, o confisco pela Gestapo de seu apartamento em Paris, onde estavam parte de sua biblioteca e muitos de seus manuscritos, e, também, mais um golpe de má-sorte, que desta vez seria fatal: enquanto convivia com a ameaça de ser deportado para a Alemanha, apesar de ter conseguido visto em Marselha para deixar a Europa e visto de trânsito para atravessar a Espanha - por onde passaria até chegar ao embarque em Lisboa - Benjamin náo portava um visto de saída francês, ainda exigido na época. Isso, em geral, não era um problema incontornável, pois havia um conhecido caminho clandestino para se chegar até a fronteira espanhola em Port Bou, que não era vigiado pela polícia francesa. Embora fosse relativamente fácil o caminho, Benjamin deve ter chegado em estado de exaustão. Chegando à fronteira junto com um pequeno grupo de refugiados, soube que a Espanha fechara suas fronteiras naquele mesmo dia e que não eram aceitos vistos expedidos em Marselha. Naquela noite, Benjamin tirou sua vida, ao que os oficiais da fronteira - impressionados com a tragédia - permitiram que o restante do grupo seguisse até Portugal. Algumas semanas depois, o embargo dos vistos foi novamente suspenso: "Um dia antes, Benjamin teria passado sem nenhum problema; um dia depois, as pessoas em Marselha saberiam que, de momento, era impossível passar pela Espanha. Apenas naquele dia particular foi possível a catástrofe" (ARENDT, 1987, p. 147-48).

Algumas frases de Kafka parecem representar essa desgraça que teimava em persistir na vida de Benjamin, mas que, também, identificavam o desespero dos povos ameaçados pelas forças nazifascistas: "A pessoa que não consegue enfrentar a vida sempre precisa, enquanto viva, de uma máo para afastar um pouco de seu desespero pelo seu destino [...] mas com sua outra mão ela pode anotar o que vê entre as ruínas, pois vê muitas coisas, e diferentes, do que as outras; afinal, está morto durante sua vida e é o verdadeiro sobrevivente" (KAFKA apud ARENDT, 1987, p. 148).

Enquanto a ampulheta contava o tempo para o inferno do holocausto, Benjamin, assim como Kafka e Kraus, criticava severamente não apenas o antissemitismo como tal - à época largamente disseminado, principalmente, na Europa - mas, também, e com mais gravidade, a reação da classe média judaica, com a qual eles [intelectuais] não se identificavam: 
Aí também não era questão da atitude apologética frequentemente vil do judaísmo oficial, com a qual os intelectuais dificilmente mantinham qualquer contato, mas a recusa mentirosa da própria existência de um antissemitismo generalizado, do isolamento da realidade organizado e efetuado com todos os recursos da auto-ilusão por parte da burguesia judaica, isolamento que para Kafka e não só para ele incluía a separação muitas vezes hostil e sempre arrogante em relação ao povo judeu, os chamados Ostjuden (judeus da Europa oriental) a quem responsabilizavam, embora se soubesse que não era verdade, pelo antissemitismo (ARENDT, 1987, p. 160).

Sobre essa classe média judia relutante em perceber a gravidade da realidade, Benjamin escreveu:

Sua função política é de estabelecer não partidos, mas panelinhas, sua função literária é produzir não escolas, mas modas, e sua função econômica é por no mundo não produtores, mas vendedores. Vendedores ou espertinhos que sabem como gastar sua miséria como se fossem ricos e que se regozijam com sua tediosa vacuidade. Não é possível se estabelecer mais comodamente numa situação incômoda (apud ARENDT, 1987, p. 161).

O sionismo e o comunismo, para os judeus daquela geração, eram as únicas formas disponíveis de rebelião. Por esse prisma, essas revoltas se afirmavam como uma fuga da ilusão para a realidade. Apesar de as circunstâncias solicitarem uma união contra o terror, entre esses dois movimentos se instaurou um hostil confronto ideológico: para os comunistas, os sionistas eram fascistas judeus, ao passo que para os sionistas os comunistas eram assimilacionistas vermelhos:

Benjamin manteve ambos os caminhos abertos para si durante anos; continuou a considerar o caminho para a Palestina muito tempo depois de ter se tornado marxista, sem se permitir ser desviado, por mínimo que fosse, pelas opinióes de seus amigos de orientação marxista, principalmente os judeus. Isso mostra claramente quão pouco lhe interessava o aspecto "positivo" dessas ideologias, e que o que lhe importava em ambos os casos era o fator "negativo" de crítica às condiçôes existentes, um caminho para fora da hipocrisia e das ilusóes burguesas, uma posição fora da instituição literária e também acadêmica. Ele era muito jovem quando adotou essa atitude radicalmente crítica, provavelmente sem suspeitar a que isolamento e solidão ela ao final o conduziria (ARENDT, 1987, p. 161-62).

Observa-se, nas cartas que escreveu, uma certa indecisão entre o sionismo e o marxismo, o que, provavelmente, deve-se à cruel percepção de que as pensadas soluções eram, além de objetivamente falsas, inadequadas à realidade. Benjamin se estabelecera nas condiçôes terríveis da realidade, esperando lá permanecer para "[...] desnaturar seus textos como álcool metílico [...] sob o risco de torná-los impróprios para consumo de qualquer pessoa entáo viva, mas com a chance de serem preservados da forma mais confiável para um futuro desconhecido" (ARENDT, 1987, p. 163).

Referindo-se à resistência contra o nazifascismo na primeira metade do século passado, nos tristes anos de culto à eugenia e de propagação de imperialismos na Europa e na Ásia, em circunstâncias de declínio moral que negaram o direito de viver de forma seletiva na Europa e em outros lugares do mundo, Benjamin (n.d.) escreveu que o espanto com o qual vinha sendo percebido o mundo em sua época náo se explicava na origem de um saber, a menos que esse saber fosse o reconhecimento de que a concepção de história donde advinha tal espanto era insustentável. Ora, em sua avaliaçáo náo haveria documento de cultura que também não pudesse ser considerado um documento de barbárie: 


\section{Tese VIII}

A tradição dos oprimidos nos ensina que o "estado de exceçâo" em que vivemos é exatamente a regra. Precisamos chegar a um conceito de História que dê conta disso. Teremos, então, diante dos olhos, a tarefa que nos cabe: produzir o verdadeiro estado de exceção; e, assim, nossa posição na luta contra o fascismo melhorará. Uma das principais razóes da oportunidade dada ao fascismo consiste afinal em que seus adversários, em nome do progresso, se relacionam com ele como se fosse uma norma histórica. O espanto ante o fato de que "ainda" seja possível no século $\mathrm{XX}$ acontecimentos como os que vivemos não é o espanto filosófico; não tem ele lugar na origem de um saber, a menos que esse saber seja o reconhecimento de que a concepção da História de que nasce um tal espanto é insustentável (BENJAMIN, n.d., p. 4).

Enfim, é importante dizer que, além de sua notável produção intelectual e poética, de sua preocupação e da constante reflexão sobre a situação mundana, Benjamin inaugurou um estilo de escrita centrado em citaçôes. Esse estilo o diferencia de escritores e de obras tidas como eruditas, em que as citaçôes apenas verificam e documentam opiniôes, relegando-se às notas. Em Benjamin, o trabalho principal estava, segundo Arendt (1987, p. 173), em "[...] arrancar fragmentos do seu contexto e dispô-los novamente de modo tal que se ilustrassem reciprocamente e pudessem provar sua raison d'être num estado, por assim dizer, de livre flutuação", como uma espécie de montagem surrealista. Esse novo método, apesar de forçar as percepçóes, seria preferível ao hábito difundido de falsificá-las.

Benjamin, ao pensar poeticamente, alimentado pelo presente, trabalha com os "fragmentos do pensamento" que extrai do passado e reúne sobre si:

Como um pescador de pérolas que desce ao fundo do mar, não para escavá-lo e trazê-lo à luz, mas para extrair o rico e o estranho, as pérolas e o coral das profundezas, e trazê-los à superfície, esse pensar sonda as profundezas do passado - mas não para ressuscitá-lo tal como era e contribuir para a renovação de eras extintas. O que guia esse pensar é a convicção de que, embora o vivo esteja sujeito à ruína do tempo, o processo de decadência é ao mesmo tempo um processo de cristalização, que nas profundezas do mar, onde afunda e se dissolve aquilo que outrora era vivo, algumas coisas "sofrem uma transformação marinha" e sobrevivem em novas formas e contornos cristalizados que se mantêm imunes aos elementos, como se apenas esperassem o pescador de pérolas que um dia descerá até elas e as trará ao mundo dos vivos - como "fragmentos do pensamento", como algo "rico e estranho" e talvez mesmo como um perene Urphänomene (ARENDT, 1987, p. 176).

Com essas palavras, redigidas por Arendt, que reverenciam a beleza da alma poética de Benjamin, finaliza-se esta breve síntese biográfica, que marca pontos cintilantes da saga de um homem dedicado a dignificar a vida humana, a despeito da dura realidade nos tempos sombrios em que viveu.

\section{Crítica à obra de arte na época das técnicas de reprodução}

É possível afirmar que, via de regra, a obra de arte sempre foi suscetível de reprodução. Ou seja, nas diferentes épocas da história humana conhecida muitos mestres reproduziram suas obras com o intuito de assegurar sua difusão; falsários as imitaram para obter lucro indevido; e discípulos as copiaram para exercitar sua arte. Todavia, revela-se como um fenômeno relativamente 
recente a acelerada ampliação das técnicas de reprodução, sobretudo a partir do século XX. Houve uma revolução no âmbito dessas técnicas, que desafiam o homem a rever seus conceitos sobre a obra de arte. No que respeita à reprodução de imagens, com a invenção da fotografia:

[...] a mão encontrou-se demitida das tarefas artísticas essenciais que, daí em diante, foram reservadas ao olho fixo sobre a objetiva. Como, todavia, o olho capta mais rapidamente do que a mão ao desenhar, a reprodução das imagens, a partir de então, pôde se concretizar num ritmo tão acelerado que chegou a seguir a própria cadência de palavras. $\mathrm{O}$ fotógrafo, graças aos aparelhos rotativos, fixa as imagens no estúdio de modo táo veloz como o que o ator enuncia as palavras (BENJAMIN, 1983, p. 06).

Em um curto espaço de tempo, o que "profetizou” Valéry ainda no século XIX se tornou uma realidade:

Tal como a água, o gás e a corrente elétrica vêm de longe para as nossas casas, atender às nossas necessidades por meio de um esforço quase nulo, assim seremos alimentados de imagens visuais e auditivas, passíveis de surgir e desaparecer ao menor gesto, quase que a um sinal (VALÉRY apud BENJAMIN, 1983, p. 06).

Apesar de a reprodução estar cada vez mais próxima da perfeição, falta-lhe, conforme Benjamin (1983), o hic et nunc (em latim: neste exato instante e local) da obra de arte, "a unidade de sua presença no próprio local onde se encontra”. A história da obra está vinculada a essa presença, que é exclusiva. A autenticidade de alguma coisa se caracteriza pelo que ela contém e que é originalmente transmissível. Com a multiplicação das cópias, um único evento se transforma num fenômeno de massas. A noção de aura pode ainda ser definida como a "única aparição de uma realidade longínqua, por mais próxima que esteja”. Destaca-se, a fim de explicar o fenômeno das massas e as noções de aura e de autenticidade em Benjamin, o seguinte trecho da obra em exame:

Encontramos hoje, com efeito, dentro das massas, duas tendências igualmente fortes: exigem, de um lado, que as coisas se lhe tornem, tanto humana como espacialmente, "mais próximas", de outro lado, acolhendo as reproduçóes, tendem a depreciar o caráter daquilo que é dado apenas uma vez. Dia a dia, impóe-se gradativamente a necessidade de assumir o domínio mais próximo possível do objeto, através de sua imagem e, mais ainda, em sua cópia ou reproduçáo. A reprodução do objeto, tal como a fornecem o jornal ilustrado e a revista semanal, é incontestavelmente uma coisa bem diversa de uma imagem. A imagem associa de modo bem estreito as duas feiçôes da obra de arte: a sua unidade e a duração; ao passo que a foto da atualidade, as duas feições opostas: aquelas de uma realidade fugidia e que se pode reproduzir indefinidamente. Despojar o objeto de seu véu, destruir a sua aura, eis o que assinala de imediato a presença de uma percepçáo, tâo atenta àquilo que "se repete identicamente pelo mundo", que, graças à reproduçáo, consegue até estandardizar aquilo que existe uma só vez. Afirmase assim, no terreno intuitivo, um fenômeno análogo àquele que, no plano da teoria, é representado pela importância crescente da estatística. $\mathrm{O}$ alinhamento da realidade pelas massas, o alinhamento conexo das massas pela realidade, constituem um processo de alcance indefinido, tanto para o pensamento, como para a intuição (BENJAMIN, 1983, p. 09-10).

Sabe-se que as antigas obras de arte serviam a rituais mágicos ou religiosos. O valor de unicidade - próprio da obra autêntica - fundava-se sobre esse ritual. Essa função da obra de arte aos poucos se desfez com a perda de sua aura. Contudo, mesmo com o passar dos séculos - como um ritual secularizado - essa ligaçáo fundamental persistiu no culto dedicado à beleza. Esse culto 
se conserva ainda hoje, apesar dos abalos que vem sofrendo, particularmente, com a invenção da fotografia, técnica que representa uma revolução nas formas de reprodução. Para Benjamin (1983, p. 11), a obra de arte, dessa forma, tende a se emancipar de sua existência parasitária imposta pela função ritualística:

Da chapa fotográfica pode-se tirar um grande número de provas; seria absurdo indagar qual delas é a autêntica. Mas, desde que o critério de autenticidade não é mais aplicável à produção artística, toda a função da arte fica subvertida. Em lugar de se basear sobre o ritual, ela se funda, doravante, sobre uma outra forma de práxis: a política.

No caso específico do filme, diferentemente do que ocorre na literatura ou na pintura, a técnica de reprodução, segundo Benjamin (1983), não apenas faculta sua difusão maciça, senão que sua técnica de produção está ligada diretamente à técnica de reprodução. Dessa maneira, é permitido e exigido, em razão dos altos custos de produção, a difusão maciça do filme. Deveras, não se compra um filme como se compra um quadro.

Com o cinema, o homem passa a agir com toda a sua personalidade viva, mas desprovido da aura, que não é reproduzida. Diferindo do teatro, no qual a aura de um personagem representado não se separa da aura do ator que desempenha esse papel, a tomada no estúdio substitui o público pelo aparelho. Dessa forma, a aura dos intérpretes se esvai e com ela a dos personagens que representam:

Como notou Pirandello, o intérprete do filme sente-se estranho frente à sua própria imagem que lhe apresenta a câmera. De início, tal sentimento se parece com o de todas as pessoas, quando se olham no espelho. Mas, daí em diante, a sua imagem no espelho separa-se do indivíduo e torna-se transportável. E aonde a levam? Para o público [...] Na medida em que restringe o papel da aura, o cinema constrói artificialmente, fora do estúdio, a "personalidade do ator"; o culto do astro, que favorece ao capitalismo dos produtores e cuja magia é garantida pela personalidade que, já de há muito, reduziu-se ao encanto corrompido de seu valor de mercadoria (BENJAMIN, 1983, p. 17).

Benjamin (1983) destaca que na literatura, em outros tempos, poucos escritores estavam diante de milhares de leitores. Entretanto, especialmente ao final do século XIX, com a ampliação da imprensa, observou-se um crescente aumento do desinteresse dos leitores para com os escritores. A partir da criação, pelos jornais, de colunas do tipo "correio dos leitores", e daí em diante:

[...] inexiste hoje em dia qualquer europeu, seja qual for sua ocupação, que, em princípio, não tenha a garantia de uma tribuna para narrar a sua experiência profissional [...] Entre o autor e o público, a diferença, portanto, está em vias de se tornar cada vez menos fundamental. A competência literária não mais se baseia sobre formação especializada, mas sobre uma multiplicidade de técnicas e, assim, ela se transforma num bem comum. Tudo isso se aplica ao cinema sem reservas, onde os deslocamentos de perspectiva, que exigiram séculos no campo literário, realizaram-se em dez anos (BENJAMIN, 1983, p. 18-19).

Uma produção cinematográfica não pode ser vista sem considerar as técnicas que a possibilitam, ou seja, as máquinas de filmar, os aparelhos de iluminação etc. Abstrair isso do espectador implicaria em confundir seu olho com a objetiva da câmera:

Para o homem hodierno, a imagem do real fornecida pelo cinema é infinitamente mais significativa, pois se ela atinge esse aspecto das coisas que escapa a qualquer 
instrumento - o que se trata de exigência legítima de toda obra de arte - ela só o consegue exatamente porque utiliza instrumentos destinados a penetrar, do modo mais intensivo, no coração da realidade (BENJAMIN, 1983, p. 20).

Aplicadas à obra de arte, as técnicas de reprodução, com efeito, alteram o comportamento das massas em relação à arte. Por exemplo, o público não separa no cinema a crítica da fruição:

Mais do que em qualquer outra parte, o elemento decisivo aqui é que as reações individuais, cujo conjunto constitui a reação maciça do público, ficam determinadas desde o começo pela virtualidade imediata de seu caráter coletivo [...] O fato de que os quadros passaram, a partir do século XIX, a serem mostrados a um público considerável corresponde a um primeiro sintoma dessa crise não apenas desfechada pela invençấo da fotografia, mas, de modo relativamente independente de tal descoberta, pela intenção da obra de arte de se endereçar às massas (BENJAMIN, 1983, p. 21).

Comparando a arte do cinema às artes da pintura e do teatro, Benjamin (1983, p. 22) sustenta:

Com relaçáo à pintura, a superioridade do cinema se justifica naquilo que the permite melhor analisar o conteúdo dos filmes e pelo fato de fornecer ele, assim, um levantamento da realidade incomparavelmente mais preciso. Com relação ao teatro, porque é capaz de isolar número bem maior de elementos constituintes. Esse fato - e é daí que provém a sua importância capital - tende a favorecer a mútua compenetração da arte e da ciência.

Com os recursos auxiliares da câmera de vídeo, é possível capturar gestos antes imperceptíveis, acontecimentos ocorridos em frações de segundos. A tecnologia do vídeo permite a experiência do inconsciente visual, da mesma forma como a psicanálise permite a experiência do inconsciente instintivo. Na presença de um quadro, as pessoas se entregam à contemplação, à associação de ideias. Já no cinema, as imagens se movimentam, não permitindo ao olho fixar uma imagem. Benjamin (1983), sobre esse tema, cita Duhamel:

Já não posso meditar no que vejo. As imagens em movimento substituem os meus próprios pensamentos [...] Trata-se de uma diversão de parias, um passatempo para analfabetos, de pessoas miseráveis, aturdidas por seu trabalho e suas preocupaçóes [...] um espetáculo que não requer nenhum esforço, que não pressupóe nenhuma implicação de ideias, não levanta nenhuma indagação, que não aborda seriamente qualquer problema, não ilumina paixão alguma, não desperta nenhuma luz no fundo dos corações, que não excita qualquer esperança a não ser aquela, ridícula, de, um dia, virar star em Los Angeles (DUHAMEL apud BENJAMIN, 1983, p. 25).

Demonstra-se, com a citação de Duhamel, a compreensão de que as massas procuram apenas diversão ao passo que a arte exige concentração. Sobre essa oposição entre diversão e concentração, Benjamin (1983) pondera que quem se encontra diante de uma obra de arte mergulha nela, penetra-a, como na lenda de um pintor chinês que se perdeu dentro da paisagem que acabara de pintar. No caso da diversão, é a obra de arte que penetra a massa.

\section{Consideraçóes finais}

As consideraçôes precedentes permitem reconhecer que Benjamin concebia, nas primeiras décadas do século XX, que constituíam aspectos de um mesmo processo histórico a proletarização crescente do homem e a ascensão das massas. $\mathrm{O}$ nazifascismo permitia a expressáo 
dessas massas, sem, contudo, ceder em relação ao regime de propriedade. Para Benjamin, se na Grécia antiga a humanidade se oferecia em espetáculo aos deuses do Olimpo, atualmente ela fez de si mesma um espetáculo, vivendo a sua própria destruição como um gozo estético de primeira ordem.

$\mathrm{Na}$ compreensão de Benjamin, embora as técnicas de reprodução viabilizem que se repita indefinidamente uma obra de arte à perfeição, essa massificação retira da obra sua autenticidade, quer dizer, "a unidade de sua presença no próprio local onde se encontra". Por essa perspectiva, a história da obra está vinculada a essa presença exclusiva. A autenticidade de alguma coisa, para Benjamin, caracteriza-se pelo que ela contém e que é originalmente transmissível. A obra reproduzida não contém a aura de autenticidade. Um único evento, com a multiplicação das cópias, transforma-se num fenômeno de massas.

Compreende-se que os espaços se encurtaram e as velocidades se aceleraram no século passado e nas últimas décadas, época em que as ficçôes são frequentemente reinventadas, porquanto o que constituía uma impossibilidade técnica hoje, talvez, possa ser realizado com tranquilidade, e quem sabe amanhã já seja considerado uma tecnologia ultrapassada. Resta perguntar, na esteira do pensamento poético e crítico de Benjamin, se as sociedades civis e os Estados soberanos algum dia serão capazes de resolverem suas divergências de forma dialogada, fitando, para além do horizonte de seus restritos interesses, uma vida digna para as pessoas, independentemente das diferenças socioculturais, econômicas, étnicas, religiosas, de gênero etc.

\section{Referências}

ARENDT, Hannah. Homens em tempos sombrios. Traduzido por Denise Bottmann. São Paulo: Companhia das Letras, 1987.

BENJAMIN, Walter. Textos escolhidos: Walter Benjamin, Max Horkheimer, Theodor W. Adorno, Jürgen Habermas. Traduzido por José Lino Grünnewald et al. São Paulo: Abril Cultural, 1983. (Os pensadores).

BENJAMIN, Walter. Sobre o conceito de história. Tradução de Paulo Schneider e Maria Luiza Armando. Ijuí: n.d. 